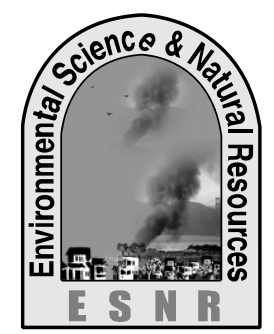

\title{
Traffic Induced Noise Pollution and its Impact on Human Health in Chittagong City Corporation
}

\author{
M. T. Islam ${ }^{1 *}$, N. Nahar ${ }^{1}$, M. J. Islam ${ }^{2}$, M. A. Islam ${ }^{3}$ and M. A. M. Hossen ${ }^{3}$
}

${ }^{1}$ Department of Environmental Science and Technology, Jessore Science and Technology

University, Jessore

${ }^{2}$ Department of Development Studies, Bangladesh University of Professionals, Dhaka

${ }^{3}$ Department of Environmental Science, Bangladesh Agricultural University, Mymensingh

"Corresponding author: tariku15221@ gmail.com

\begin{abstract}
Noise is one of the most pervasive environmental problems. Excessive noise has become one of the major concerning of urban life. Chittagong, the port city of Bangladesh, is one of the nosiest cities of the country. With economic development, the situation is expected to worsen farther. Motor vehicles are the principal source of noise pollution in the city. This study illustrates the level of noise pollution in Chittagong city corporation and its impacts on city dwellers. The noise level is measured at 25 locations of Chittagong city road areas. Time-weighted average noise levels have been measured at the roadside. From the study it was observed that the highest noise level in the roadside in Chittagong city was about $93 \mathrm{~dB}$ found at AK Khan Circle and Agrabad circle, which far exceeded the acceptable limit of $60 \mathrm{~dB}$ set by the Government of Bangladesh. The level of noise pollution is closely related with traffic volume, particularly with the number of heavy vehicles like trucks, buses as well as auto rickshaw have been observed during the study. Questionnaire survey was done during the study to determine the health impacts on the city dwellers. Most of the common problems, the dweller suffering from noise pollution are headache, bad temper, sleeplessness, aggravation, hearing problems etc.
\end{abstract}

Key words: Environmental problems, Human health, Noise pollution

\section{Introduction}

Noise is all around us. It is unavoidable part of our daily lives and has increasingly become a major burden on the quality of lives. Noise is derived from the Latin word "nausea" implying unwanted sound or sound that is loud, unpleasant or unexpected (Sing et al., 2004). Noise pollution is defined as form of air pollution that is an audible unwanted sound that poses a threat to a person's health and well-being (Goines et al., 2007). It generally defined as a sound in the wrong place in the wrong time that causes general feeling of annoyance and irritation, fatigue and damage to the auditory mechanisms (Chauhan et al., 2010). Noise is described in terms of loudness and pitch and noise exposure is measured using a logarithmic decibel (dB) scale (NIDC, 2010). Noise pollution is not only a problem in the developed countries (Peterson,1983) it is also a problem for developing countries like Bangladesh (Uddin et al., 2009) with rising population growth, the urbanization in Bangladesh is also taking place at a quick pace. With growth and urbanization of our cities and towns, there has been a rapid increase in the traffic volume on the roadways. Although transportation is an indispensable part of the modern society, its benefits may be overshadowed by its negativities and is a cause for concern for the community. Noise pollution from road traffic streams is one such negative consequence. Noise levels in general have increased over the years the noise levels in the cities have increased at about $1 \mathrm{~dB}$ per year for the last 30 years (Wang et al., 2005). Today the noise generated from traffic is a major source of environmental pollution. This is substantiated by results emanating from the continuous monitoring of equivalent noise levels at a number of sensitive, residential, commercial and industrial sites during the day and at night. Having developed as a cumbersome condition that has become unacceptable to society, noise pollution has manifested itself in the urban environment. Noise has infect been a constant threat since the industrial revolution (Singh and Rao, 2001). It is worthy to note that the noise is a silent killer and prolonged exposure to low frequency noise can cause either permanent or temporal damage to hearing. The effect of noise on human emotion ranges from negligible through annoyance and anger to psychologically disruptive (Akpan et al., 2003). Many studies have revealed that extended exposure to noise pollution may cause auditory and no auditory disorders such as temporary and permanent hearing loss (Keipert, 2008) sleep disruption (Bhargava and Gupta, 1998). Vertigo, agitation, weariness, hypertension, gastrointestinal system problems, cardiac arrhythmia, nervous and psychic disorders (Roozbahani et al., 2009) and so on. Frequent exposure to high level of noise causes severe stress on the auditory and nervous system. But most often noise problem is ignored because of many others environmental problem to deal with and for countries like Bangladesh this is true. While $65 \mathrm{~dB}$ is the noise level for conservation heard at a distance of one meter, $125 \mathrm{~dB}$ gives the sensation of pain in the ear and $150 \mathrm{~dB}$ might kill a human being (Miller, 1979). However, very few studies have been conducted on noise pollution and its source inventory in all over the country. In this aspect the study has an attempt to make a noise inventory of Chittagong City corporation area. Moreover the study includes the level of noise pollution in Chittagong city corporation area and analyzes its level of severity on human health. The main aim of this study is to investigate noise pollution and its effects on the Chittagong city corporation area. Keeping the above views in mind the present work was done setting the following objectives: to determine the level of noise pollution in Chittagong City Corporation area and analyzing its level of severity; to quantify the effects of noise pollution; to ascertain the impact of noise pollution on the surrounding neighborhood, and to recommended appropriate strategies to control the level of noise pollution in the city. 


\section{Materials and Methods}

\section{Study area}

Chittagong is the second-largest city and principal seaport of Bangladesh. It is located at the estuary of the Karnaphuli River in southeastern Bangladesh. It faces the Bay of Bengal to its west. The city has a population of over 6.5 million people. It is the administrative capital of Chittagong Division and the main city of Chittagong District. Chittagong was a major administrative, transportation and commercial centre in the Bengal Presidency in British India.

In recent years, the metropolitan region of Chittagong has emerged as one of the fastest-growing cities in the world. With the development and expansion of port facilities and the opening of new trade routes, Chittagong has ambitions of emerging as a leading regional and global economic hub.

\section{Measuring instruments}

A calibrated sound level meter - Lutron SL-4001 sound level meter was used to collect noise level data

\section{Sampling location}

For this study Chittagong city corporation area south eastern part of Bangladesh was selected. There were 25 sampling points selected road area.

\section{Data collection}

Noise measurements were performed between 7 am to $10 \mathrm{pm}$ for different road areas and 7 am to $6 \mathrm{pm}$ for schools and colleges and hospitals when there was no rain or wind. Sound pressure level was manually recorded at intervals of 15 minute.

\section{Data collection from questionnaire survey}

As pre scheduled questionnaire was developed for the study .person to person interview was conducted. Total numbers of hundred respondents (Including Shopkeeper, house wives, Businessman, Driver, Transport stuff, Day laborer, doctor) were randomly selected from different points of the study area. The questioner focused on sources, causes, effects, and environmental risk factors for health.

\section{Secondary data}

Secondary data and information was collected from different governmental and nongovernmental organizations, statistical report, articles, published paper, official records, literature review and internet. However noise pollution problems are new to Bangladesh. So data availability is rare for this study.

\section{Data analysis}

The collected data was processed, analyzed and interpreted for final presentation with the help of statistical techniques and equation with percentage and graphs.

\section{Results and Discussion}

\section{Noise level in different road areas of Chittagong city corporation (7am-10pm)}

\section{AK Khan Circle}

In Fig. 1. noise level (7am-10pm) of AK khan circle has been shown. The above figure shows that the highest noise level of $\mathrm{AK}$ khan circle is $93 \mathrm{~dB}$ and lowest noise level is $65 \mathrm{~dB}$. AK Khan is an intercity bus terminal area which is the entrance of Chittagong city. It falls under mixed zone. According to Ahmed (1998) the limit of acceptable noise level is $60 \mathrm{~dB}$ in mixed zone areas.

\section{Agrabad circle}

Agrabad is a mixed zone area where several shopping malls situated, Highest and lowest average value of this area is $93 \mathrm{~dB}$ and $63 \mathrm{~dB}$ respectively. In Fig. 2. it has been also shown that noise level of this area is always above the accepted level during ( $7 \mathrm{am}-10 \mathrm{pm})$. The maximum value was noticed at $6 \mathrm{pm}-7 \mathrm{pm}$. Minimum value was noticed at $7 \mathrm{am}-8 \mathrm{am}$.

\section{Noise level variation of road areas of Chittagong city corporation}

Fig. 3. shows noise level variation from 7 am-10 pm of twenty five road areas of Chittagong City Corporation.Twenty five road points are AK khan circle, Alangker circle, Boropole circle, Customs circle, Barek building circle, Agrabad circle, Choumuhoni circle, Deyan hat circle, Tigerpass circle,Ispahani circle, WASA circle, GEC circle, 2NO. gate circle, Muradpur circle, Boddar hat circle, New market circle, Kotowali circle , Andarkilla circle, Cheragi hill, Chawk bazaar, Kazir dewri, Kodomtoli Bus Stand, Jamal khan circle, CRB hill area, DC hill. Maximum noise level of these areas is $93 \mathrm{~dB}, 88 \mathrm{~dB}, 82 \mathrm{~dB}, 92 \mathrm{~dB}, 90 \mathrm{~dB}, 93 \mathrm{~dB}, 88$ $\mathrm{dB}, 88 \mathrm{~dB}, 87 \mathrm{~dB}, 86 \mathrm{~dB}, 86 \mathrm{~dB}, 90 \mathrm{~dB}, 86 \mathrm{~dB}, 90 \mathrm{~dB}$, $86 \mathrm{~dB}, 86 \mathrm{~dB}, 84 \mathrm{~dB}, 86 \mathrm{~dB}, 86 \mathrm{~dB}, 82 \mathrm{~dB}, 86 \mathrm{~dB}, 78$ $\mathrm{dB}, 66 \mathrm{~dB}, 78 \mathrm{~dB}$ respectively. The minimum noise level of these areas is $65 \mathrm{~dB}, 68 \mathrm{~dB}, 60 \mathrm{~dB}, 67 \mathrm{~dB}, 62$ $\mathrm{dB}, 63 \mathrm{~dB}, 63 \mathrm{~dB}, 62 \mathrm{~dB}, 56 \mathrm{~dB}, 62 \mathrm{~dB}, 62 \mathrm{~dB}, 76 \mathrm{db}$, $72 \mathrm{~dB}, 65 \mathrm{~dB}, 67 \mathrm{~dB}, 60 \mathrm{~dB}, 58 \mathrm{~dB}, 65 \mathrm{~dB}, 65 \mathrm{~dB}, 62$ $\mathrm{dB}, 64 \mathrm{~dB}, 55 \mathrm{~dB}, 66 \mathrm{~dB}, 51 \mathrm{~dB}, 51 \mathrm{~dB}$ respectively. Highest noise level found at Agrabad and AK Khan Circle $93 \mathrm{~dB}$, during $6 \mathrm{pm}-7 \mathrm{pm}$ at Agrabad area and 8 pm-9 pm at AK Khan area. Minimum noise level was found at CRB Hill area $51 \mathrm{~dB}$. According to Ahmed (1998), acceptable limit for noise level in mixed zone area is $60 \mathrm{~dB}$.

Average Noise Level (7am-10pm) of Different Road Areas of Chittagong City Corporation

Fig. 4. represents the average noise level of 25 road areas of Chittagong City Corporation. Most of the places are above the accepted level. Highest average value is $81 \mathrm{~dB}$ and lowest average value is $64.2 \mathrm{~dB}$. Most of the places noise level is around $80 \mathrm{~dB}$. 
AK Khan Circle

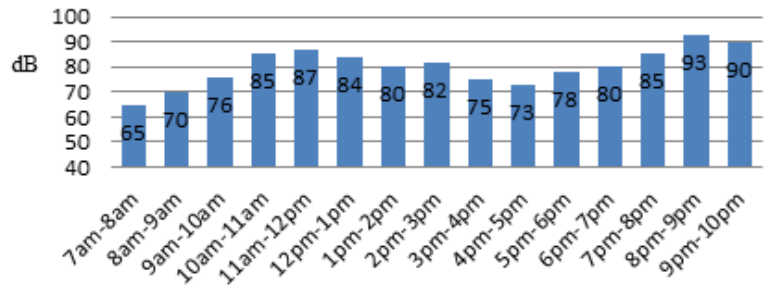

Fig. 1. Noise level of AK Khan Circle (7am-10pm)

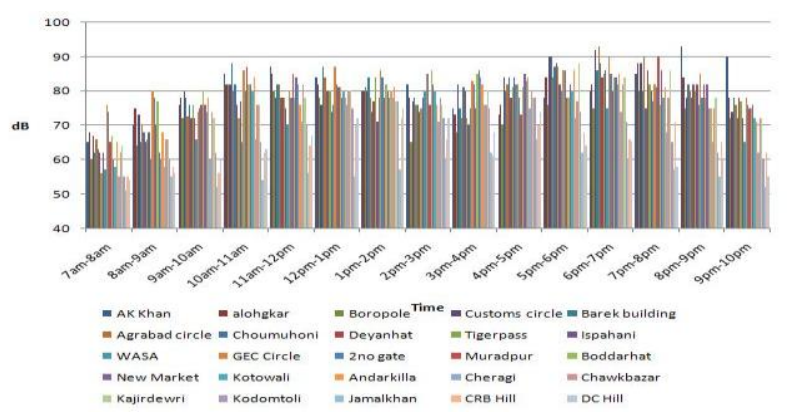

Fig. 3. Noise level variation (7am-10pm) of road areas of Chittagong city corporation

\section{Impact of noise pollution on the people of Chittagong city corporation \\ Survey of general public}

100 members of the general public surveyed during the study. Among them $60 \%$ were male and $40 \%$ were female (Most of the interviewers were male because it was easier to get responses from the men than the women). 50\% respondents with age range from 25-35, $30 \%$ of the respondents with age range $36-45$ and $20 \%$ were from 15-25 are shown in Fig. 5.

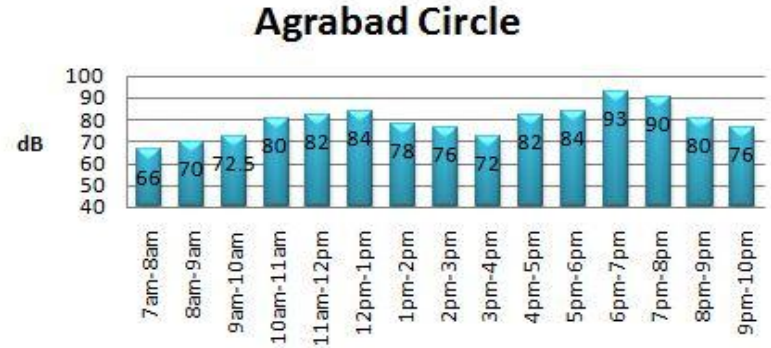

Fig. 2. Noise level of Agrabad Circle (7am-10pm)
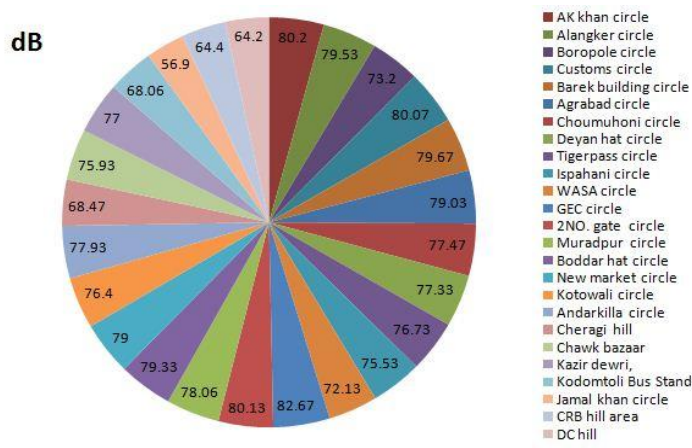

Fig. 4. Average noise level (7am-10pm) of different road areas of Chittagong city corporation

Almost all of the respondents responded that noise pollution is a problem, less than $12 \%$ saying that noise pollution is not a problem. Between both sexes, on average $80 \%$ considered noise pollution as unbearable phenomena and $12 \%$ responded as bearable are shown in Fig. 6. The respondents themselves personally suffered from many problems caused by noise pollution. The most common problems they were suffering from headache $(80 \%)$, bad temper $(25 \%)$, hearing problem $(35 \%)$, and sleeplessness $(40 \%)$ are shown in Fig. 7.

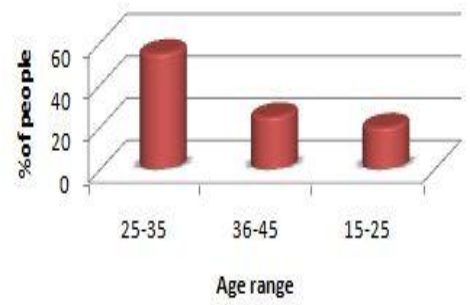

Fig. 5. Respondent by age

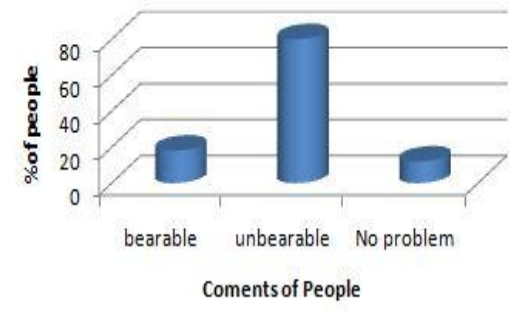

Fig. 6. Is Noise pollution a problem?

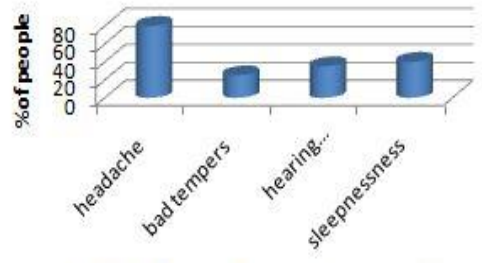

Problems suffering from people

Fig. 7. Problems suffering from Noise pollution
To identify the main three causes of noise pollution, the respondents were mentioned motor vehicle (90\%), followed by miking (40\%), industrial activities $(30 \%)$, construction $(20 \%)$, and others $(10 \%)$ are shown in Fig. 8. To abatement of noise pollution problems peoples were expressed their suggestion. To improve noise pollution situation, $55 \%$ suggested for rising of awareness, $8 \%$ suggested for banning of hydraulic horn and $35 \%$ for administrative measure and $2 \%$ did not any comment (Fig. 9).
Noise pollution is a severe environmental problem in Chittagong city. Peoples were hearing suffering from various problems like hearing problems, sleeplessness, headache and bad temper. For hearing problem $40 \%$ peoples visited to doctor last year. 20\% visited for sleeplessness and rest $40 \%$ did not visit to doctor though they were being suffering from various problems are shown in Fig. 10. 


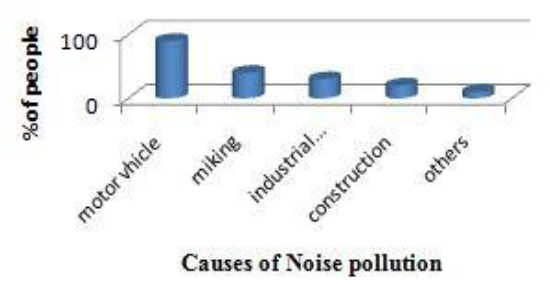

Fig. 8. Causes of Noise pollution

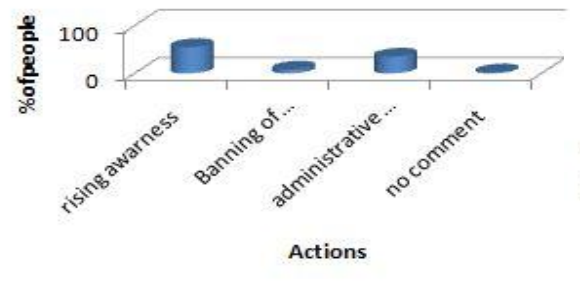

Fig. 9. Ways to reduce Noise pollution
People visited to doctor last year

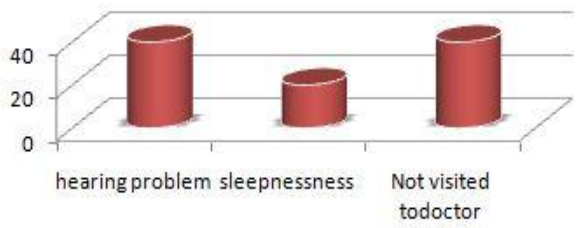

Fig. 10. People visited to doctor last year for Noise related problems

\section{Conclusions}

Noise may be described as sound without agreeable quality or as an unwanted or undesired sound. With the rising population on the Chittagong city number of vehicles are increasing. But number of roads or size of the roads is not increasing. As a result noise level is increasing day by day. The study was performed by a noise level meter (Lutron SL-4001). Highest noise level was found at Agrabad and AK khan circle 93dB. A prescheduled questioner survey was performed. The study observes that most of the people are unaware about noise pollution. But many people are affected by noise pollution's impact. Unawareness of the population about noise pollution is also a factor for increasing noise pollution. It is necessary to grow awareness about noise pollution. The results of the study show that the level of noise in Chittagong city

\section{References}

Ahmed, K. 1998. "A study of noise pollution in Dhaka city". Department of Environment (DOE), Dhaka, Bangladesh.

Akpan, A. O.; Onuu M. U.; Menkiti, A. I. and Asoquo U. E. 2003. Measurments and Analysis of Industrial Noise and its Impact Workers in Akwalbom State, South Eastern Nigeria. Nig. journal of phys, 15(2): 41-45.

Bhargava and Gupta. 1998. Environmental pollution and human health's. Chand and Company Ltd. ( $1^{\text {st } E d n .), ~ p p .16-18 ~ . ~}$

Chauhan, A.; Pawar, M.; Kumar, D.; Kumar, N. and Kumar, R. 2010. "Assesment of Noise level status in different Areas of Moradabad city," Reportland opinion; 2(5), 5961p.

Goines, L. and Haglar, L. 2007. Noise Pollution: A Modern Plague. Southern Medical journal. March; 100(3):287-293.

Keipert, J. A. 2008. The harmful effect of noise in a children's ward. J. Paediatr. Child Health, 21 (2): 101-103.

Miller, J. D. 1979. An Effect of noise on people. In T. D. Rossing (E), Environmental Noise control: corporation area is fur above the accepted level of Department of Environment, Bangladesh. Even in silent zone like hospitals and school areas, noise levels are much higher than the accepted level. This has serious implication on general health as well as mental health and well being of the citizens of Chittagong city corporation area. Urgent measures should be taken to control the noise pollution. Special measures should be taken to construct road and road side faces buildings. Traffic rules should be imposed strictly to control horn sounds. Road signs about maximum noise speed and horn must be place at respective areas. Public awareness is needed. Awareness is also needed for Transport workers. Overtaking tendency must be stopped. This study will be helpful to grow awareness, and strategy about noise pollution.

selected reprints. Stony Brook, NY: American Association of physics teachers, 124-147pp.

NIDC Fact sheet. 2010. Noise induced Hearing loss.U.S. Department of health and Human services, National Institute of Health, National Institute of Deafness and other communication disorders.

Peterson, Y. 1983. Speech the legibility of normal listeners and persons with impaired hearing in traffic noise. Journal of Sound vibration. 90: 341-360.

Roozbahani, M. M.; Nassiri, P. and Shalkouhi, P. J. 2009. Risk assessment of workers exposed to noise pollution in a textile plant. Int. j.Environ. Sci. Tech., 6(4): 591-596.

Sing, N. and Davarj, S. C. 2004. Hum. Ecol. 16(3): 181187.

Singh, N. M. and Rao, S. N. 2001. A Reconnaissance of Traffic noise pollution in the city of patna, Indian journal of Environmental health, 8(1): 33p.

Uddin, M. J.; Rahman M. A. and Roy, R. 2009. Noise Mapping and their Interpretations of Sahbagh area, Dhaka, Bangladesh. J. of Env. Res., 7:43-51

Wang, L. K.; Pereira, Norman. C. and Yung. T. 2005. "Advanced air and Noise pollution", Human press, Totowa, Newjersey. pp.304-308. 